\title{
Effect of Construction Type on Structural Behaviour of R.C Bubbled One-Way Slab
}

\author{
Amer M. Ibrahim*,1, Murtada A. Ismael ${ }^{2}$, Humam A. Abdul Hussein ${ }^{3}$ \\ ${ }^{1}$ Department of Civil Engineering, College of Engineering, Diyala University, Diyala, Iraq. \\ ${ }^{2}$ Department of Civil Engineering, College of Engineering, Diyala University, Baghdad, Iraq. \\ ${ }^{3}$ Department of Civil Engineering, College of Engineering, Diyala University, Diyala, Iraq.
}

Amereng76@yahoo.com

\begin{abstract}
Using Bubbles in the slab is a revolutionary method of eliminating concrete from the middle of conventional slab as this concrete does not perform any structural function, thereby dramatically reducing structural dead weight. This research presents experimental study to investigate the effect of construction type on the strength and behaviour of bubbled one-way slabs. The experimental program consists of testing four slabs with dimensions of $1850 \mathrm{~mm} \times 460 \mathrm{~mm} \times 110$ $\mathrm{mm}$. One1of the tested slabs was conventional slab (without bubbles), two bubbled slabs with different types of construction (simple and filigree bubbled slabs) and the remaining one is filigree bubbled slab strengthened with steel cage. The bubbles were made of recycled plastic balls. The experimental results show that the stiffness reduction factor for all the bubbled slabs was (0.87), this leads to decrease the ultimate strength of bubbled slabs and to be smaller than that of the solid slab by $4.4 \% 69 \%$ and $1.7 \%$ respectively. Also an increase in deflection at yield load $\left(\Delta_{\mathrm{y}}\right)$ by about $(10 \%$ to $12 \%)$, at the same time the crack load is found to be decreased by (13\% to $40 \%$ ). The simple bubbled slab is more efficient when compared with filigree bubbled slab. Also the results show that the use of steel cage in filigree bubbled slab gives an increase in the ultimate load by $69 \%$ and an increase in the ultimate deflection by about $77 \%$ when compared with filigree bubbled slab without steel cage.
\end{abstract}

Keywords: Bubble deck; Steel cage; Spherical; Filgree.

\section{Paper History:}

(Received: 18/10/2017; Accepted: 12/12/2017)

\section{Introduction}

One of the important structural members that makes the structural space is the slab, which is one of the largest members that consumes concrete (Chung, et at., 2011). The first design limitation when designing a reinforced concrete slab, is the span between the columns. When designing large spans between columns, the use of very thick slabs and or support beams are often required.
This will lead to an increase in the dead weight of the structure by requiring the use of large amounts of concrete. Heavier structures are less resistant for seismically forces than the lighter ones, because of a larger dead load often increases the magnitude of inertia forces. Incorporating support beams also contribute to larger floor-to-floor heights, which consequently increases the costs of finish materials [1].

For decades, many attempts had been made to create biaxial hollow slabs for the sake of weight reduction. Many attempts used a less heavy material like expanded polystyrene were laid between the bottom and top reinforcement, like waffle slabs/grid slabs. Only waffle slabs were having certain use in the market, but its use was very limited because of resistance reduction towards shear, local punching and fire [2].

In 1990ies, a new system was invented by a Danish engineer Jorgin Breing, the so called Bubble-Deck system, for eliminating the above problem. The Bubble-Deck system uses spherical balls made of recycled plastic to create air voids while providing strength through arch action. These bubbles can decrease the dead weight up to $35 \%$ and can increase the capacity by almost $100 \%$ with the same thickness [3].

The Bubble-Deck system offers a wide range of advantages in building design and during construction. There are a number of green attributes including; reduction in total construction materials, use of recycled material, lower energy consumption reduced $\mathrm{CO}_{2}$ emissions, less transportation and crane lifts that make Bubble-Deck more environmentally friendly than other concrete construction techniques [4].

\section{Experimental Program}

\subsection{Materials}

\section{A-Cement}

The type of cement which is used in this work was the Ordinary Portland cement (type I), manufactured by Tasluja factory (Iraq). The chemical composition and physical properties are 
conforming to the requirements of the (Iraqi Standard Specification I.Q.S No.5, 1984) [5].

\section{B-Fine aggregate (sand)}

The fine aggregate used in this work was obtained from Al-Sidor region as natural sand. It has fineness modulus of 2.38. The grading and physical properties of fine aggregate are conformed to the limits of the (Iraqi Specification I.Q.S No.45, 1984) [6].

\section{C-Coarse aggregate (gravel)}

In this study, natural gravel which is used as coarse aggregates with a maximum size of $(12.5 \mathrm{~mm})$. Natural gravel was obtained from AlSidor region. The gravel was cleaned by washing and dried on the air. The physical properties and grading of this aggregates satisfied the requirement of the (Iraqi specification No. 45, 1984) [6].

\section{D-Admixture}

Two types of admixture were used in the recent study:-

\section{- Superplasticizer}

High Performance Superplasticizer Concrete Admixture (HPSCA), used throughout this work with trade name (ViscoCrete $®-5039)$. It is a third generation of high performance dual action superplasticizer for concrete which can also produce self-compacting concrete. Also, it is free from chlorides and complies with (ASTM C494 type $G$ and F). A substantial increase in slump and flowability without segregation were observed when the concrete mixture containing superplasticizer.

\section{- Lime stone}

In the present experimental work, crushed limestone powder (LSP) brought from local market was used as a filler for concrete production. Filler is used in SCC to increase the amount of fine material in the mixture, so enhance its cohesiveness, and change for the better segregation resistance. The particle size of Limestone powder is less than $0.125 \mathrm{~mm}$ according to (EFNARC, 2002) [7].

\section{E-Plastic Balls}

In the recent study to make voids inside the slabs, plastic balls were manufactured from recycled plastic material with spherical shape of diameter $80 \mathrm{~mm}$. The purpose of using plastic material is to conserve energy because it takes far less energy to reprocess recycled materials into new material than to process virgin materials. Also, recycle helps to reduce global warming and reduce air pollution by reducing the amount of industrial work that must be completed to create a new product. The ball must have enough stiffness to safely support the applied load in the phases before and after pouring.

\section{F-Steel Reinforcement}

For all slabs, deformed steel bar are used as the steel reinforcement at top and bottom of the slabs. The main reinforcement has a size of $\varnothing 10 \mathrm{~mm}$, but the secondary reinforcement and steel cage size was $\varnothing 4 \mathrm{~mm}$. The mechanical properties of the tested steel bar are given in Table 1 .

Table 1 Mechanical properties of steel reinforcement.

\begin{tabular}{|c|c|c|c|c|c|}
\hline $\begin{array}{c}\text { Bar } \\
\text { Diameter } \\
(\mathbf{m m})\end{array}$ & $\begin{array}{c}\text { Measured } \\
\text { diameter } \\
(\mathbf{m m})\end{array}$ & $\begin{array}{c}\text { Yield } \\
\text { Stress } \\
(\mathbf{M P a})\end{array}$ & $\begin{array}{c}\text { Strain at yield } \\
\text { stress } \\
\text { (microstrain) }\end{array}$ & $\begin{array}{c}\text { Ultimate } \\
\text { Stress } \\
(\mathbf{M P a})\end{array}$ & $\begin{array}{c}\text { Modulus } \\
\text { of elasticity } \\
(\mathbf{G P a})\end{array}$ \\
\hline 4 & 4.45 & 390 & 2000 & 464.7 & 195 \\
\hline 10 & 10.08 & 470 & 2361 & 683.3 & 199 \\
\hline
\end{tabular}

\subsection{Specimens Description}

This study contains four slab specimens. One was a solid slab, another three were bubbled slabs with different type of construction. The tested parameters include the construction type (simple and filigree construction) and the presence of shear reinforcement (steel cage) in the filigree bubbled slab. Table 2 and Figure 1 explain the description and details of the tested slabs. It is important to mention that the reduction in concrete volume is the same for all bubbled slabs.

Table 2 Description and symbols of specimens

\begin{tabular}{|c|c|c|}
\hline Slab code & Description of Specimens & Shear reinforcement \\
\hline SS & Solid slab & -- \\
\hline BS & Simple bubble slab & --- \\
\hline F.BS & Filligre bubble slab & --- \\
\hline F.BS.S & Filligre bubble slab with steel cage & $\emptyset 4 @ 105 \mathrm{~mm}$ \\
\hline
\end{tabular}




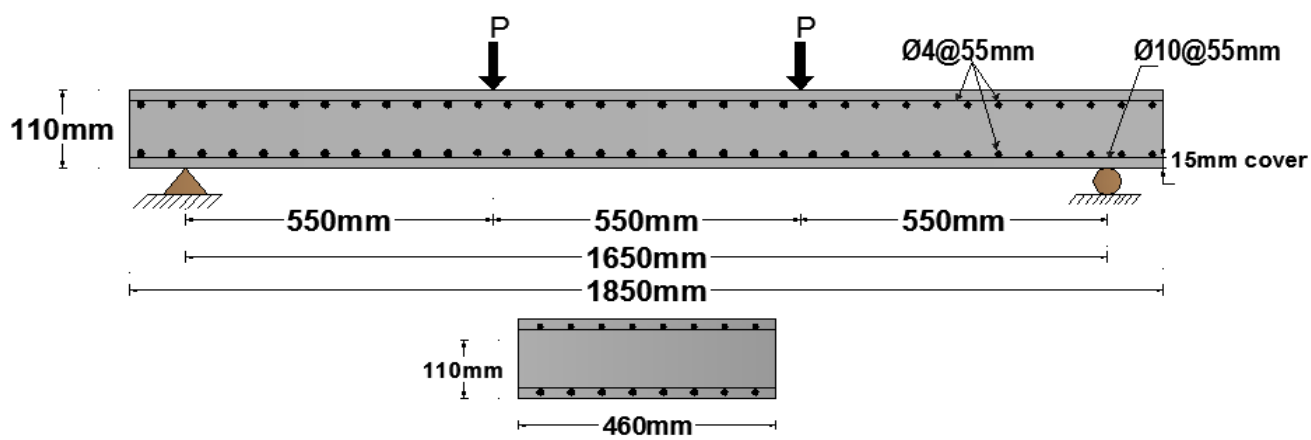

(a) Solid slab
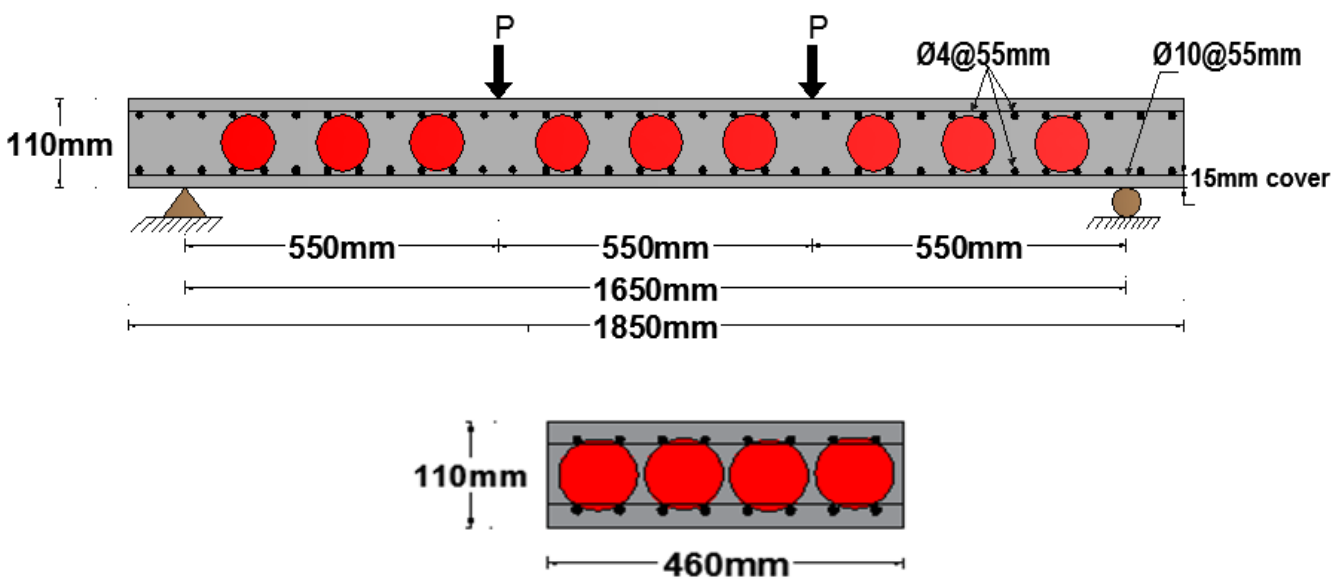

(b) Simple bubbled slab

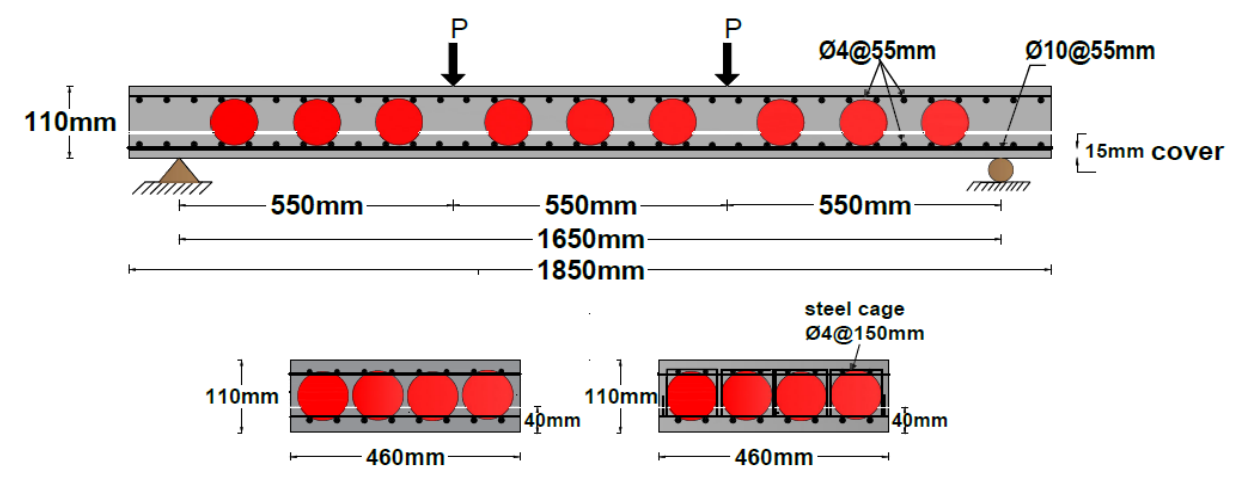

(c) Filigree bubbled slab

Figure 1: Reinforcement details of the slabs

\subsection{Concrete Mix}

All the tested slabs were made fully with selfcompacted concrete (SCC), the design compressive strength of $29 \mathrm{MPa}$ was used. The concrete mix quantities are presented in Table 3. For each series of casting, the specified compressive strength is measured by testing three cylinders

Table 3 Concrete mix quantities per cubic meter.

\begin{tabular}{|c|c|c|c|c|c|c|}
\hline $\begin{array}{c}\text { Concrete } \\
\text { symbol }\end{array}$ & $\begin{array}{c}\text { Cement } \\
\mathrm{Kg} / \mathrm{m}^{3}\end{array}$ & $\begin{array}{c}\text { Sand } \\
\mathrm{Kg} / \mathrm{m}^{3}\end{array}$ & $\begin{array}{c}\text { Gravel } \\
\mathrm{Kg} / \mathrm{m}^{3}\end{array}$ & $\begin{array}{c}\text { Limestone } \\
\mathrm{Kg} / \mathrm{m}^{3}\end{array}$ & Water & Superplasticizer $\mathrm{Kg} / \mathrm{m}^{3}$ \\
\hline $\mathrm{SCC}$ & 300 & 850 & 670 & 320 & 200 & 1.85 \\
\hline
\end{tabular}




\section{$1.4 \quad$ Test Specimen}

The slabs were tested at (28 days) age, they were prepared by cleaning them and coating with white color, in order to reveal the propagation of cracks. The slabs were simply supported over clear span of $1650 \mathrm{~mm}$ and were tested under two concentrated loads applied at each third. The load was applied and the readings taken every $(5 \mathrm{kN})$. At each increment the manual measurements were recorded, which include the applied load, deflection, crack width, steel and concrete strains. After failure the load indicator was decreased or stopped in recording and the deflection increased quickly without any increase in the applied load.

\section{Results and Discution}

\subsection{Ultimate Load Capacity}

The results of the tested slabs of this study are listed in Table 4. Test results show that the ultimate load of bubbled slabs (BS and F.BS) are less than that of solid slab by $4.4 \%$ and $69.5 \%$ respectively. This shows that the simple bubbled slab construction in slab (BS) gives the best result when compared with filigree bubbled slab (F.BS). The large decrease in ultimate load of F.BS is due to sliding between the two layers which leads to a decrease in the flexural stiffness of it. The presence of steel cage in filigree bubbled slab (F.BS.S) leads to increase the ultimate load by $69 \%$ more than that without, but still less than solid slab by about $1.7 \%$. The large increase in ultimate load of F.BS.S is due to the presence of steel cage that ensures efficient bond between the two concrete layers and hence preventing horizontal sliding and increasing the shear resistance.

Table 4 Results of test slabs.

\begin{tabular}{|c|c|c|c|c|c|c|c|c|}
\hline $\begin{array}{l}\text { Slab } \\
\text { code }\end{array}$ & $\begin{array}{c}\text { First Crack } \\
\text { load }(\mathrm{KN})\end{array}$ & $\begin{array}{l}\text { Yield } \\
\text { load } P_{y} \\
(k N)\end{array}$ & $\begin{array}{l}\text { Yield } \\
\text { deflection } \\
\Delta_{\mathrm{y}}(\mathrm{mm})\end{array}$ & $\begin{array}{l}\% \\
\text { Increase } \\
\text { in } \Delta y\end{array}$ & $\begin{array}{c}\text { Ultimate } \\
\text { load } \\
\mathbf{P}_{\mathbf{u}}(\mathbf{k N})\end{array}$ & $\begin{array}{l}\% \\
\text { Decrease } \\
\text { in } P_{u}\end{array}$ & $\begin{array}{c}\text { Ultimate } \\
\text { deflection } \\
\Delta_{\mathrm{u}}(\mathbf{m m})\end{array}$ & $\begin{array}{l}\% \\
\text { Inc } \\
\text { rea } \\
\text { se } \\
\text { in } \\
\Delta_{u}\end{array}$ \\
\hline SS & 15 & 75 & 11.6 & --- & 115 & --- & 28.4 & --- \\
\hline BS & 13 & 71 & 13 & 12 & 110 & 4.4 & 34.8 & $\begin{array}{l}22 . \\
5\end{array}$ \\
\hline F.BS & 10 & --- & --- & --- & 35 & 69.5 & 9.39 & $\begin{array}{l}- \\
66\end{array}$ \\
\hline F.BS.S & 9 & 71 & 12.8 & 10.34 & 113 & 1.7 & 42.13 & $\begin{array}{l}48 . \\
3\end{array}$ \\
\hline
\end{tabular}

\subsection{Load - Deflection Relationships}

increase is due to the presence of plastic balls in BS, which leads to a decrease of the flexural rigidity of the bubbled slab. In contrast with filigree bubbled slab (F.BS) in which the ultimate deflection is less than that in solid slab and bubbled slab by about $66 \%$ and $73 \%$ respectively. This reduction in ultimate deflection is due to the sliding between the two concrete layers, which acts to form multilayers, each layer will work as an individual slab resulting in lower flexural stiffness. The effect of using steel cage in slab (F.BS.S) shows increasing in the magnitude of ultimate deflection to be more than SS and BS by about $32.5 \%$ and $17 \%$ respectively.
The deflection was measured at the centre of tested slabs by dial gauge, and readings from this gauge were recorded for each load increment.

Generally, there are three main stages that can be seen in the load-deflection curve, first a linear zone relationship up to the appearance of first crack at the tension face of tested slabs. Second a linear zone had been seen after the first crack appearance. At the advanced stages of loading, a rapid increase in deflection with small increment in load had been noticed. At failure the deflection increases rapidly without any increase in load.

Figure 2 and Table 4 show that the ultimate deflection for bubbled slab (BS) is more than that of the solid slab (SS) by about $22.5 \%$. This 


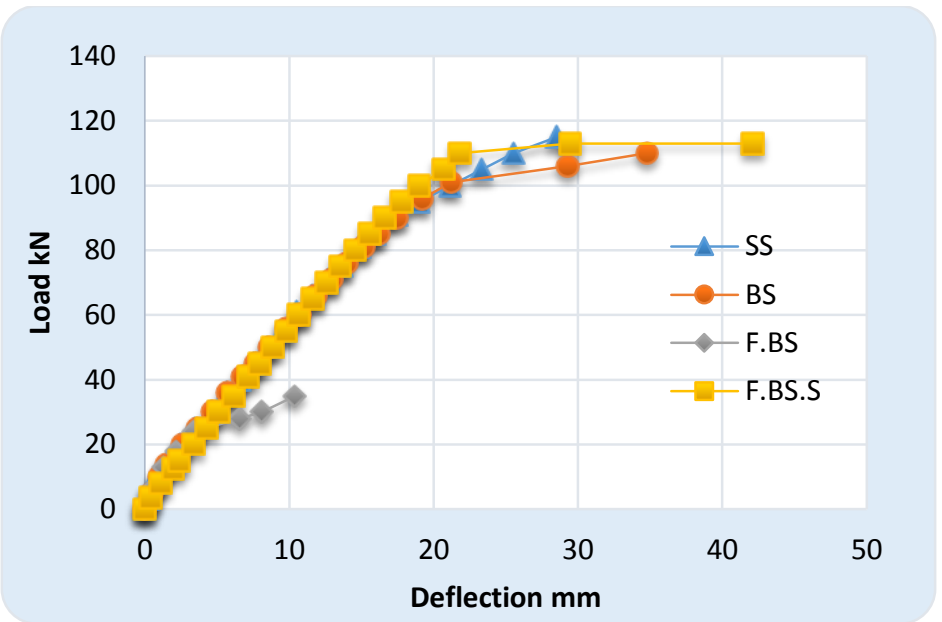

Figure 2: Load-deflection relationship for solid slab and bubbled slabs

\subsection{Average Concrete Surface Strains}

Concrete surface strain were measured by using two strain gage types (PFL-30-11-3L) installed at middle top surface of the slabs. Figure 3 shows that the bubbled slab specimens give an increase in the concrete surface strain at all stages of loading over that of the solid slab specimen. This is due to the presence of plastic balls that reduce the volume of concrete in the compression zone of bubbled slab specimens.

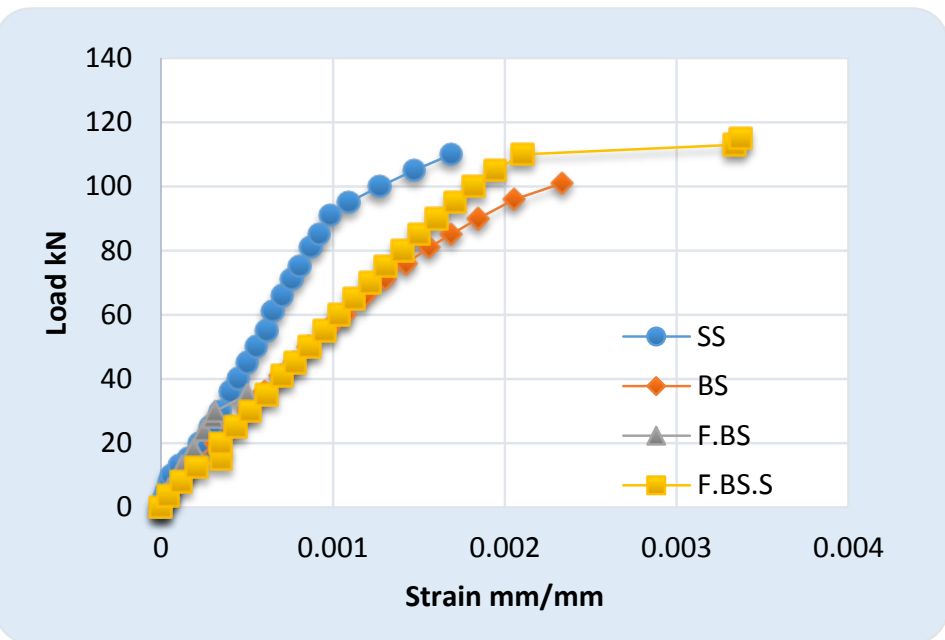

Figure 3 Load-average concrete strain curve for all slabs specimens

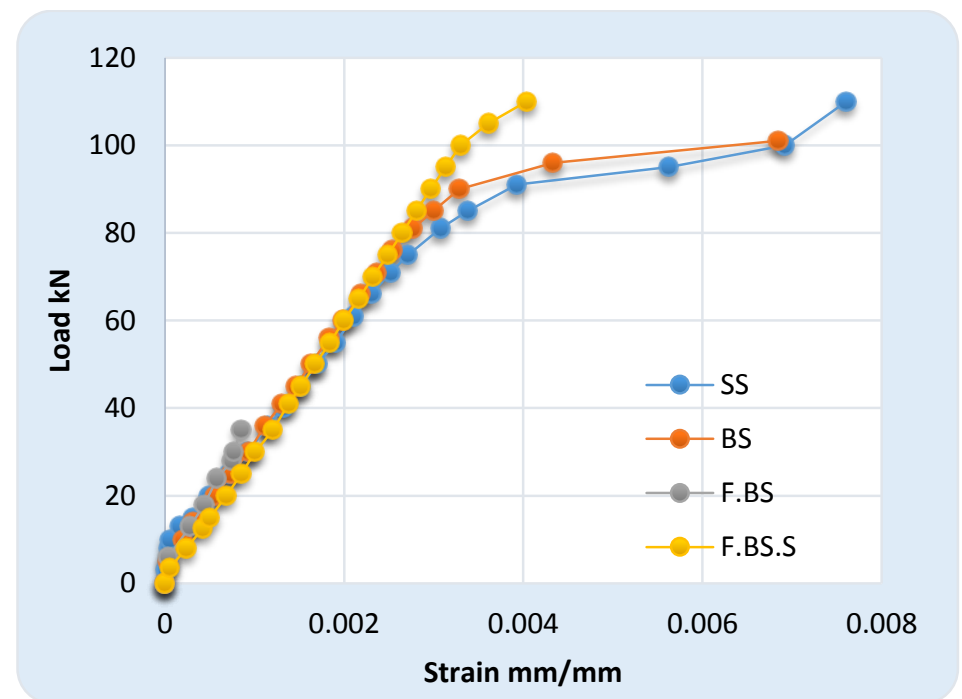

Figure 4: Load-steel strain curve for all slab specimens 


\subsection{Steel Reinforcement Strain}

Steel reinforcement strains were measured by using two electrical resistance strain gage types (PFL-10-11-3L) placed in the middle of two intermediate longitudinal reinforcing bars. Figure 4 reveals that, the strain in steel reinforcement bars in all slab specimens is very small until crack load $(13 \mathrm{kN})$. After that, abrupt changes in strain readings were recorded. The strain in slab (F.BS) doesn't reach to yield strain $(E y=2361 \mu \varepsilon)$ because the sliding had occurred before yield of the longitudinal reinforcement. In contrast with slabs (SS, BS and F.BS.S) which reach to this value, this is because the type of failure for these slabs are flexural. The ultimate strain for slabs (BS, F.BS and F.BS.S) is smaller than solid slab by about $10 \%, 88 \%$ and $46.9 \%$ respectively.

\subsection{Crack Pattern and Failure Mode}

The initial cracking of all tested slabs was first observed in the tension zone of the slab near the centre of slab. In the solid slab first flexural crack initiated at $(15 \mathrm{kN})$, at this stage of loading the tensile stress in concrete reaches the modulus of rupture value and cracking starts in the zone of maximum tensile stress. The bubbled slabs (BS, F.BS and F.BS.S) have a decrease in the first crack load when compared with the solid slab by about $6.7 \%, 6.7 \%$, and $16 \%$ respectively. This is due to the presence of plastic balls which act on reducing the concrete volumes in the tension zone. In slab (F.BS) the crack width starts to decrease after the sliding, but in (SS, BS and F.BS.S) the crack width continues to increase until failure. The mode of failure for SS, BS and F.BS.S were flexural, but sliding failure occurs in the F.BS because of joint weakness between the two layers of this slab. Figure 5 and Figure 6 illustrates the mode of failure and crack patterns of solid and bubbled slabs respectively and the sliding failure in filigree bubbled slab.
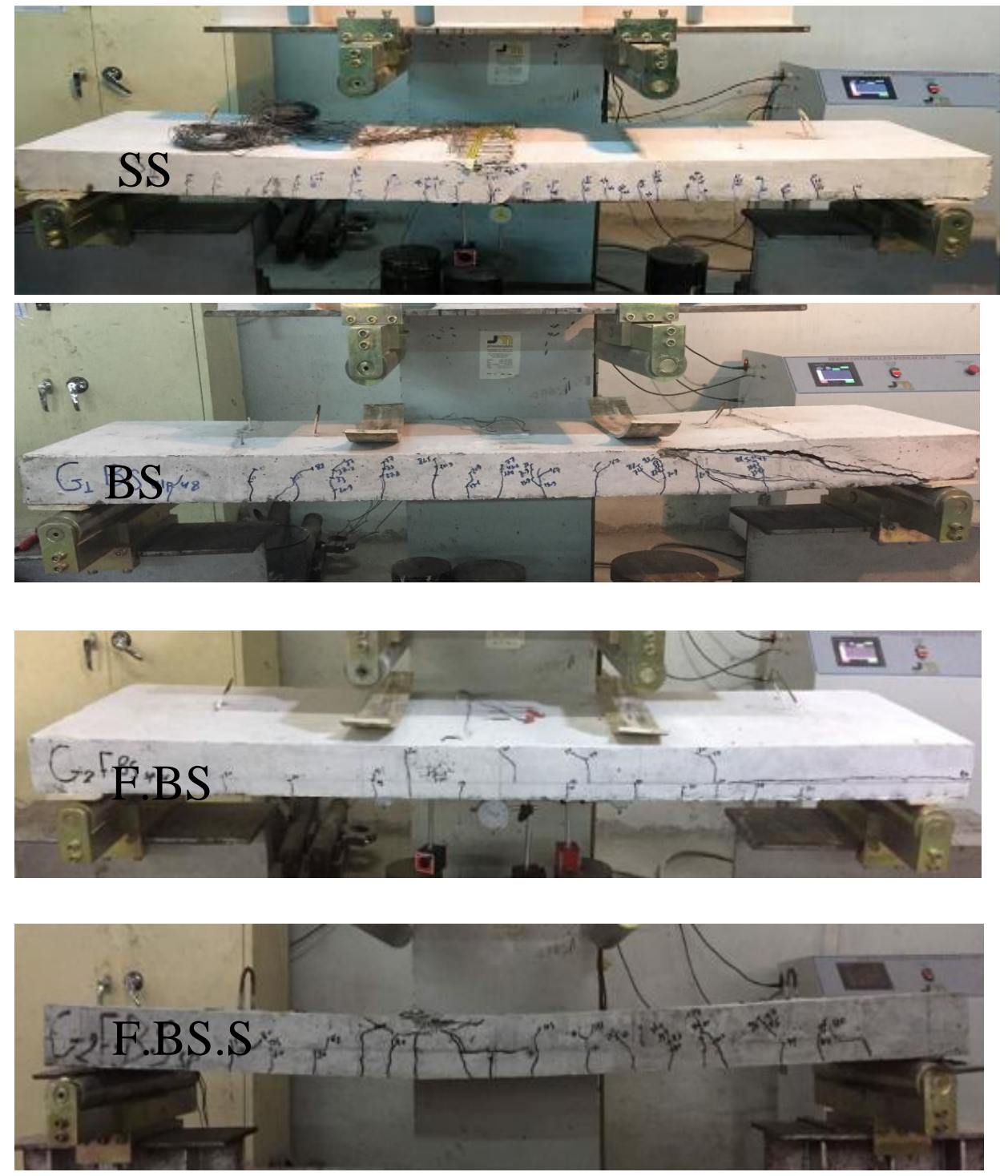
Figure 5: Crack pattern and mode of failure of SS, BS, F.BS and F.BS.S, respectively

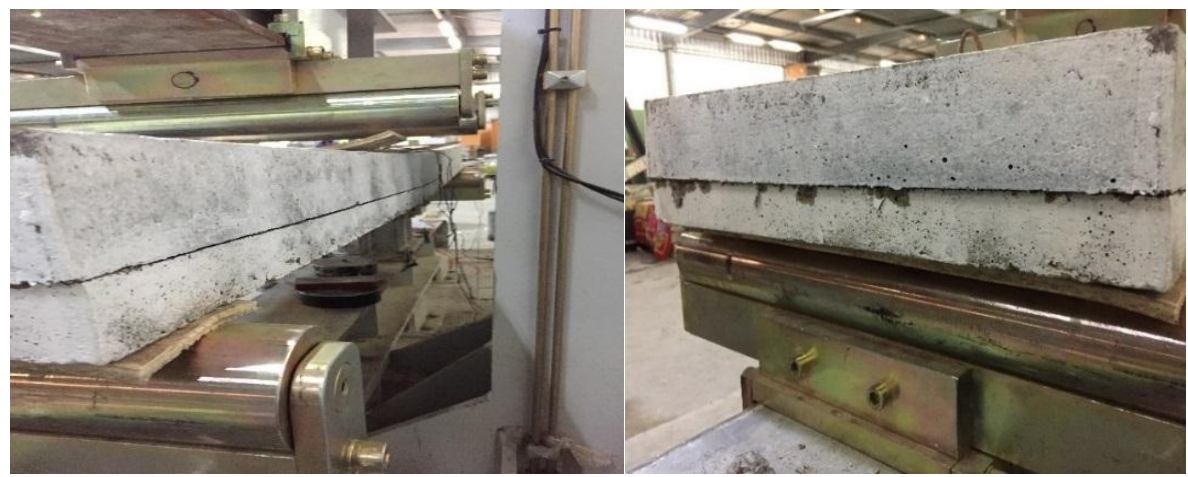

Figure 6: Sliding between two layers of concrete in F.BS

\section{Conclusion}

1. The decrease in the ultimate strength of bubbled slabs (BS, F.BS and F.BS.S) are $4.4 \%, 69 \%$ and $1.7 \%$ respectively when compared with the solid slab.

2. The deflection at yield load $(\Delta y)$ for bubbled slabs is slightly more than that in solid slab.

3. The simple bubbled slab construction gives the best results when compared with the filigree construction.

4. The effect of using steel cage in filigree bubbled slabs improves the load bearing capacity to be approximately the same as that of the solid slab.

5. Using a $1 \mathrm{~kg}$ of recycled plastic balls replaces $460 \mathrm{~kg}$ of concrete. Thus, avoiding the cement production and allows a decrease in global $\mathrm{CO} 2$ emission. Hence this technology is environmentally green and sustainable.

6. Reduction of material consumption enables to fasten the construction time and reduces the overall cost. In addition, it reduces the dead weight which allows for smaller size of building foundation.

\section{Acknowledgment}

This work was supported by University of Diyala, Civil Engineering Department, which is gratefully acknowledged.

\section{References}

[1].Midkiff, C. J., Plastic voided slab systems: applications and design. (M.Sc. Thesis, Kansas University), 2013.

[2].Joseph, A. V., Structural behaviour of bubbled deck (Doctoral dissertation, st. Joseph's college), 2016.

[3].Lai, T., Structural behaviour of Bubble Deck ${ }^{\circledR}$ slabs and their application to lightweight bridge decks (Doctoral dissertation, Massachusetts Institute of Technology), 2010.

[4].Ibrahim, A. M., Ali, N. K., \& Salman, W. D., Flexural capacities of reinforced concrete two-way bubble deck slabs of plastic spherical voids. Diyala Journal of Engineering Sciences, 6(02), (2013), p.p 9-20.

[5].Iraqi Specifications No. (5), Portland Cement, the Iraqi Central Organization for Standardization and Quality Control, Baghdad-Iraq, 1984.

[6].Iraqi Specifications No. (45), Aggregates from Natural Sources for Concrete and Building Construction, the Iraqi Central Organization for Standardization and Quality Control, Baghdad-Iraq, 1984.

[7].EFNARC, Specification and Guidelines for Self-Compacting Concrete, Association House, 99 West Street, Farnham, Surrey, London, UK, February 2002. 